\title{
The investigation of car movement trajectories after contact in the case of collisions with stationary safety barriers
}

\author{
A. Tautkus \& Z. Bazaras \\ Kaunas University of Technology, Panevėžys Institute, Lithuania
}

\begin{abstract}
Car collisions with immovable obstacles are described. One of the most frequent cases is sidelong collision with road fencings and kerbs. Such road accidents are caused by the wrong choice of speed on road turns, skidding due to road and weather conditions, etc. Certain issues occur while investigating such road accidents: the place of the collision, the speed before the accident, the car movement trajectory after the collision etc. These issues are dealt with in this paper. With the help of computer software, different car accidents with road safety barriers have been modeled and the trajectories of car movement are defined in this paper.
\end{abstract}

Keywords: road accident, parameters of collision, movement trajectory.

\section{Introduction}

To increase safety in the city streets and country roads different stationary safety barriers and bollards have been installed in roadsides and over bridge sides. Though they play an important safety function, one type of collisions is car contact with such elements. There are a lot more stationary barriers: wayside trees, traffic stanchions, utility poles, bus-shelters, different structures etc. At the moment of a car collision with stationary obstacles hard impact strain appears which determines serious injuries to people and various degrees of damage to cars. The reasons for such collisions are different: high speed, bad driving conditions, poorly maintained cars etc. In Lithuania such collisions account for about $12-13 \%$ of all road accidents [1]. 
The information to investigate the reasons and mechanisms of car collisions can be gathered by analysing real accidents or modeling different probable situations. The last-mentioned way is becoming more and more popular because it allows information to be gathered resulting in conclusions and predictions [2].

The results of car collisions with a stationary obstacle are presented in this paper. Two cases are analysed: collisions with sidelong barriers and collisions with round road elements. The movement trajectories of cars have been drawn.

\section{Modeling and investigation of collisions and their movement trajectories}

The evaluation of car movement trajectories after contact is a very important factor for road accident investigations. The evidence of the accident lets one estimate the positions of vehicles before and after the collision, which helps define car speed before the impact. The computer modeling of collisions is performed for evaluation of the car movement trajectories after the impact. The modeling is performed with the help of software. It was noticed that the trajectory of a car after contact depends on its speed and on the collision angles. Because of that, collisions were modeled with different car speeds: $36 \mathrm{~km} / \mathrm{h}, 50$ $\mathrm{km} / \mathrm{h}$ and $90 \mathrm{~km} / \mathrm{h}$, as well as collision angles: $10^{\circ}, 20^{\circ}, 30^{\circ}, 45^{\circ}$.

\subsection{Investigation of car movement trajectories after contact in the case of collision with stationary obstacle (road fencing)}

Traffic accidents are modeled at a low collision speed $-36 \mathrm{~km} / \mathrm{h}$, at an allowed speed in towns $-50 \mathrm{~km} / \mathrm{h}$, and at a higher speed $-90 \mathrm{~km} / \mathrm{h}$. The car movement trajectories after the accident are presented in figures $2-4$.

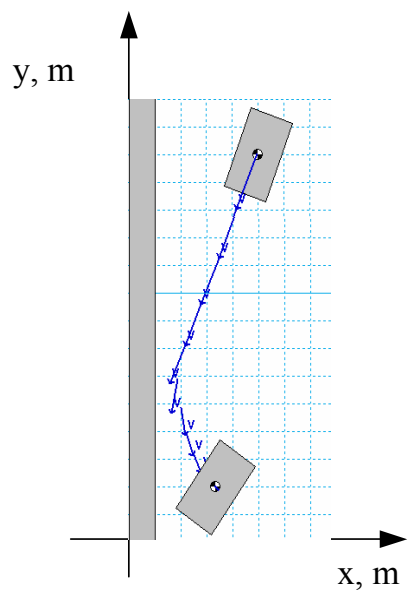

Figure 1: Model of collision with stationary obstacle (road fencing). 


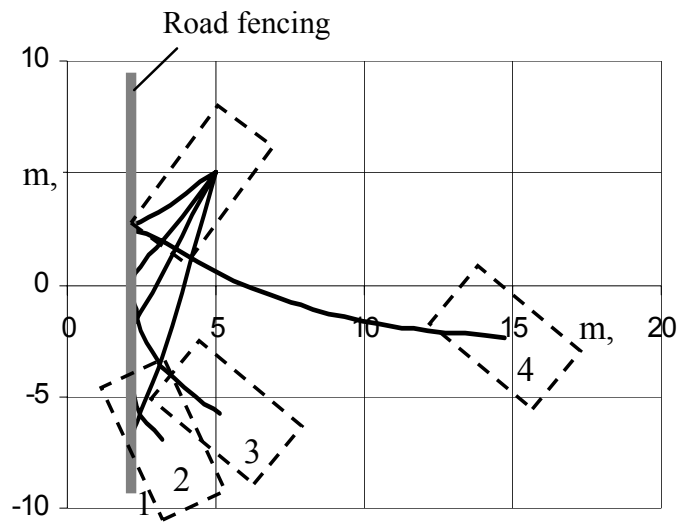

Figure 2: Trajectories drawn by car centers of gravity at the moment of collision with a stationary obstacle, when the speed before the contact $36 \mathrm{~km} / \mathrm{h}$ and collision angles equal: $1-10^{\circ}, 2-20^{\circ}, 3-30^{\circ}$,

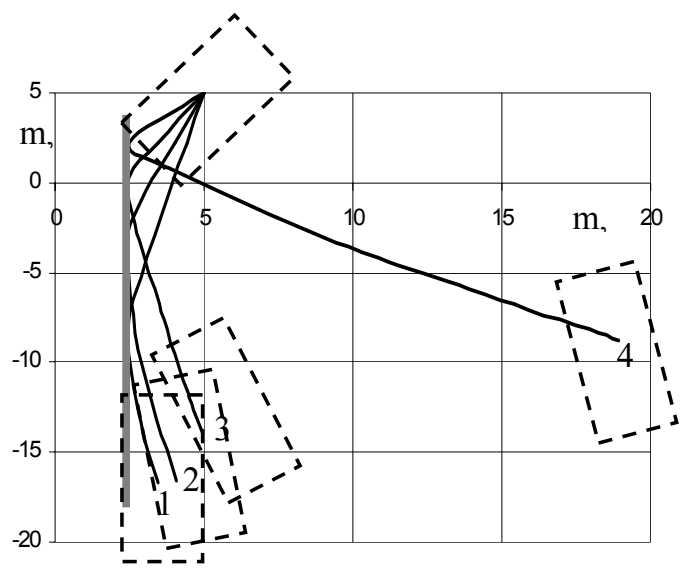

$4-45 .^{\circ}$

Figure 3: Trajectories drawn by a car's center of gravity at the moment of collision with a stationary obstacle, with the speed before the contact of $50 \mathrm{~km} / \mathrm{h}$ and collision angles equal: $1-10^{\circ}, 2-20^{\circ}, 3-$ $30^{\circ}, 4-45^{\circ}$.

The starting conditions were created as close as possible to the real traffic accidents. The speed of the car until hitting the obstacle was: $\mathrm{v}=36 \mathrm{~km} / \mathrm{h} ; 50$ $\mathrm{km} / \mathrm{h} ; 90 \mathrm{~km} / \mathrm{h}$;

- Car mass: $\mathrm{m}=1300 \mathrm{~kg}$;

- Collision angles: $10^{\circ}, 20^{\circ}, 30^{\circ}, 45^{\circ}$; 
- $\quad$ Time of modulation: $2 \mathrm{~s}$;

- $\quad$ Car width: $\mathrm{H}_{\mathrm{g}}=1,8 \mathrm{~m}$;

- Car length: $\mathrm{L}_{\mathrm{g}}=5 \mathrm{~m}$;

- Diameter of round obstacle $\mathrm{d}=0.45 \mathrm{~m}$;

- Aerodynamic coefficient: $\mathrm{c}_{\mathrm{w}}=0.4$;

- Road conditions - dry asphalt;

- Impedance of rolling: $\mathrm{f}=0,015$;

- Cohesion coefficient $\mathrm{f}_{\mathrm{x}}=0,4[3]$;

- $\quad$ Longitudinal road slope $\alpha_{\text {lon. }}=0^{0}$;

- Latitudinal road slope $\alpha_{\text {lat. }}=0^{0}$;

- Hit recovery coefficient $\mathrm{k}=0.3[4,5]$.

Having analyzed the results it is obvious that the loss of speed after impact depends on the initial speed of a car and the angle of collision. The bigger collision angles the higher speed loss is after the hit. From the car movement trajectories after the modeled accident it is obvious that the character of the trajectory depends on: the angle of collision, the car speed before the impact. The bigger the angle between the movement direction and the road fencing, the bigger the deflection of the trajectory appears. This is noticed in all the analysed cases when the collision speed was $36 \mathrm{~km} / \mathrm{h}, 50 \mathrm{~km} / \mathrm{h}$ and $90 \mathrm{~km} / \mathrm{h}$. The smaller contact angle, the more time a car is skidding along the side surface of the road fencing. When the collision speed is low $(36 \mathrm{~km} / \mathrm{h})$ and the contact angle is $10^{\circ}$ the car is skidding along the side surface of the road railing and stops without moving away from it.

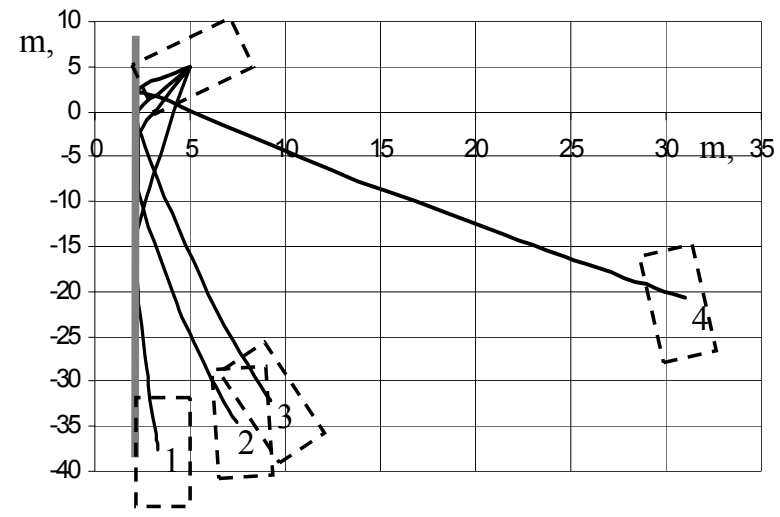

Figure 4: Trajectories drawn by car's center of gravity at the moment of collision with a stationary obstacle, when the speed before the contact $90 \mathrm{~km} / \mathrm{h}$ and collision angles equal: $1-10^{\circ}, 2-20^{\circ}, 3-30^{\circ}$, $4-45^{\circ}$. 
As has been mentioned before, the location of the vehicle after impact does not depend upon the angle of collision but also on its speed. The diagrams demonstrate that when the speed increases almost 3 times, deflection to the side increases almost twice. This fact is observed in all cases analysed when the collision angles with a stationary road element was equal to: $1-10^{\circ}, 2-20^{\circ}, 3-$ $30^{\circ}, 4-45^{\circ}$.

\subsection{Investigation of car movement trajectories after contact in the case of collision with round obstacle (tree, bollard etc.)}

Car collisions with round obstacles can be put into two groups: central and noncentral collisions. The examples of each group are shown in figures 5 and 6 [6].
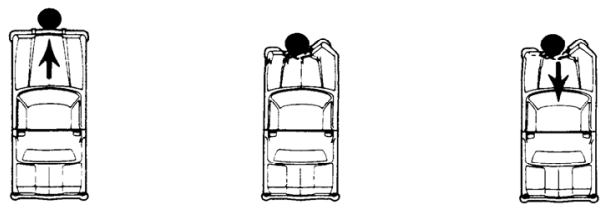

Figure 5: Central car collision with a tree, a bollard, etc.: a - first contact, $\mathrm{b}$ - maximum engagement, c- final contact.
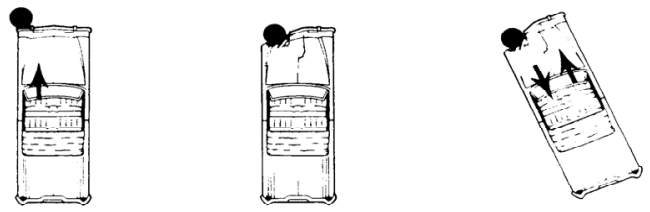

Figure 6: Non-central car collision with a tree, a bollard, etc.: a - first contact, $\mathrm{b}$ - maximum engagement, c- final contact.

In the case of a central collision the axis of an obstacle and a car is in one line which goes through the centre of the car. After impact a car usually moves in the same direction, it does not turn around. In the case of a non-central collision (fig. 6) the axis of an obstacle and a car is not in the same line. After impact a car being under the centrifugal force begins to turn and its moving trajectory becomes very complicated. Having assessed this fact, and with the help of computer software, central and non-central collisions were modeling. During the investigation the trajectory of a car's movement and its speed before contact were defined. The results, when the axis of a car and an obstacle is in line (central collision), when the difference between the axis of an obstacle and a car is $50 \%$ and $100 \%$ (non-central collision) are introduced in this paper. The example of computer modeling is shown in figure 7. 


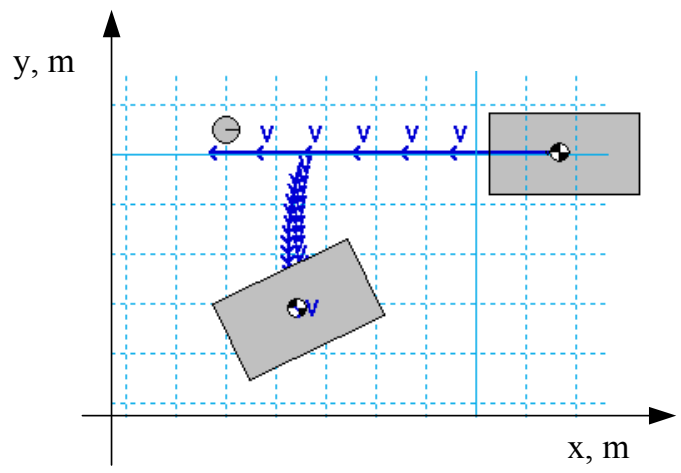

Figure 7: Model of collision with round obstacle (tree, bollard, etc.).

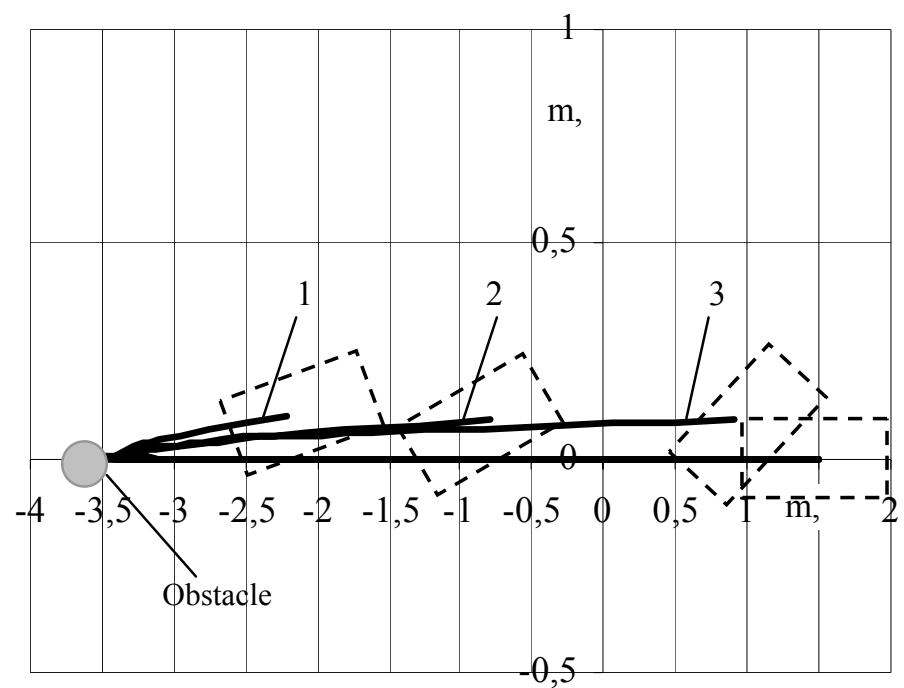

Figure 8: Trajectories drawn by a car's center of gravity at the moment of collision with a stationary obstacle, when the axis of an obstacle and a car is in line and speed before the contact is $1-36 \mathrm{~km} / \mathrm{h}$, $2-50 \mathrm{~km} / \mathrm{h}$ and $3-90 \mathrm{~km} / \mathrm{h}$.

The results show (fig. 8, 9) that the trajectory of car movement after contact with a round obstacle depends on the position of collision, the difference between the axis of an obstacle and a car and car speed before contact. Other parameters (coefficient of adhesion with road paving, car tightness and obstacle tightness etc.) influencing on the situation of the accident were thought as constant.

In the case when the difference between the axis of an obstacle and a car is in one line (central collision) (fig. 8) a car after contact does not turn around and its 
trajectory of movement is opposite the trajectory before contact. A car moves back and the distance of this movement depends on car speed before contact (fig. 8).

In the case when the difference between the axis of an obstacle and a car is not in one line, a car starts moving round after contact. Its movement trajectory depends on the difference between the axis of an obstacle and a car as well as on car speed before contact. When the difference between the axis of an obstacle and a car is $50 \%$ and speed before the contact is $50 \mathrm{~km} / \mathrm{h}$, a car moves athwart the initial direction (fig. 9). When speed is $90 \mathrm{~km} / \mathrm{h}$ and more, it starts moving around and moves forward of the obstacle (fig. 9). The same car movement has been noticed when the difference between the axis of an obstacle and a car is 100 $\%$ and a car touches an obstacle with its side. In this case car speed before contact has a bigger influence on its movement trajectory after contact (fig. 10).

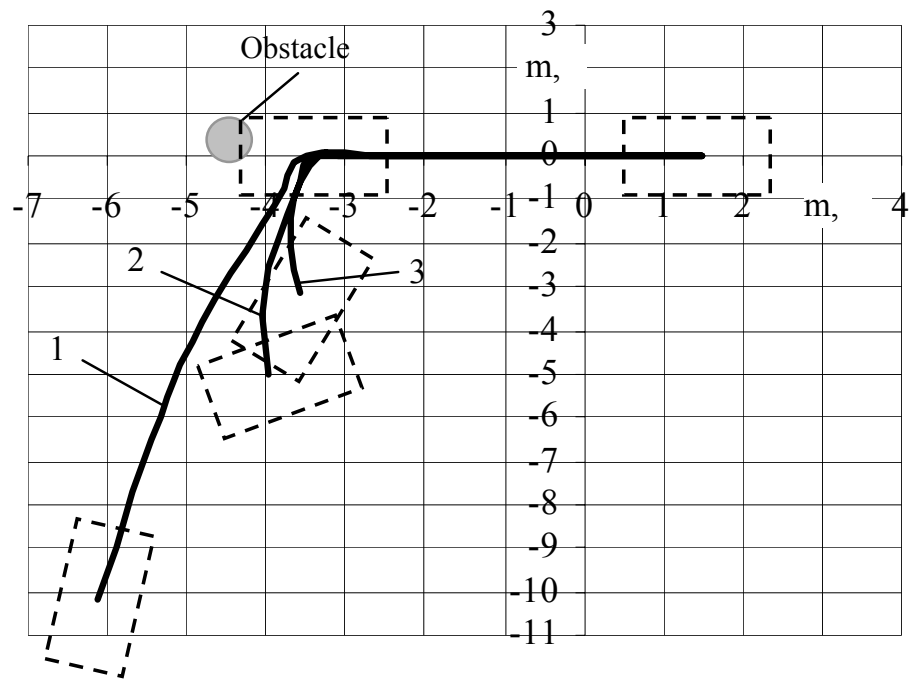

Figure 9: Trajectories drawn by a car's center of gravity at the moment of collision with a stationary obstacle, when the difference between the axis of an obstacle and a car is $50 \%$ and speed before the contact is $1-36 \mathrm{~km} / \mathrm{h}, 2-50 \mathrm{~km} / \mathrm{h}$ and $3-90 \mathrm{~km} / \mathrm{h}$.

\section{Conclusions}

Having performed the modeling of the collision with a stationary road element at certain conditions, it has been defined that a car's movement trajectory depends mainly on the conditions of the collisions and the speed of a car before it 
contacts with the obstacle. The bigger the angle between the movement direction and road fencing, the bigger the side deflection of the trajectory. The bigger the speed of the vehicle before the collision, the longer its movement trajectory after it hits the obstacle.

Having performed the calculation it was defined that in side collisions with stationary obstacles the weight of a vehicle does not have an influence on the movement trajectory after the impact; while in a case of the collision of two moving cars the weight of both influences on the trajectories of movement after the impact.

Car movement trajectory after contact with a round obstacle depends on the position of collision, on the difference between the axis of an obstacle and a car and car speed before contact.

After the collision with a stationary barrier a car often hits another vehicle, pedestrians or a building etc., which creates even more harm and damage. Roadmen should pay attention at this fact and design barriers, poles, light bollards which could reduce the impact effects.

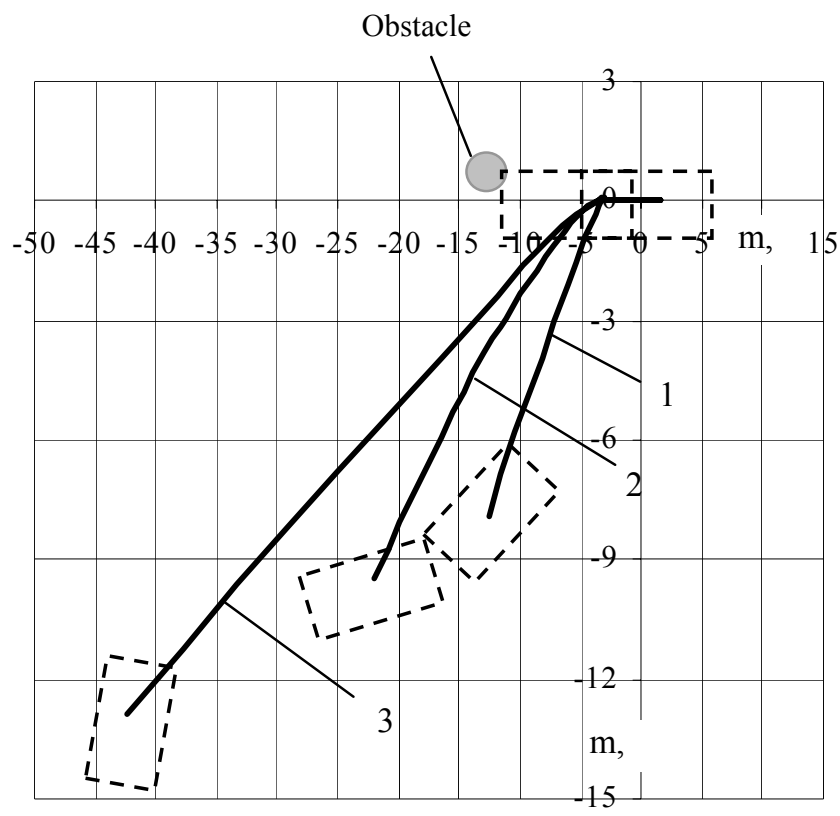

Figure 10: Trajectories drawn by a car's center of gravity at the moment of collision with a stationary obstacle, when the difference between the axis of an obstacle and a car is $100 \%$ and speed before the contact: $1-36 \mathrm{~km} / \mathrm{h}, 2-50 \mathrm{~km} / \mathrm{h}$ and $3-90 \mathrm{~km} / \mathrm{h}$. 
Urban Transport XIII: Urban Transport and the Environment in the 21st Century 565

\section{References}

[1] Tautkus A., Jurkauskas A. Evaluation of car crash parameters in the case of collision. TRANSPORT. Vilnius: Technika, 2002, XVII t., No. 3, p. 91-95.

[2] Blundell M. \& Harty D., The Multibody systems approach to vehicle dynamics. Elsevier: Great Britain, 518 p.

[3] Shang Liu C. Peng H. Road friction coefficient estimation for vehicle path prediction. Journal Vehicle System Dynamics, Vol. 25 Suppl., 1996, p. 413-425.

[4] James A. Neptune. Crush stiffness coefficients, restitution constants and a revision of CRASH 3 and SMAC. SAE Paper 98-0029.

[5] Neades J. Calculating stiffness coefficients from barrier test data. Accident reconstruction Journal Vol. 4, No. 5, 1992, p. 35-42.

[6] David A. Casteel, Steven D. Moss. Basic Collision Analysis and Scene Documentation. Lawyers and Judges publishing company, U. S. 1999, p. 109-111. 